\title{
DESENHOS E REPRESENTAÇÕES SOCIAIS ACERCA DA EDUCAÇÃO AMBIENTAL
}

\section{DRAWINGS AND SOCIAL REPRESENTATIONS ON ENVIRONMENTAL EDUCATION}

\section{Iraelza F. Coelho Monteiro}

Mestre em Desenvolvimento Humano pelo Programa de Educação e Desenvolvimento Humano (UNITAU), Taubaté-SP, Brasil ORCID: https://orcid.org/0000-0001-5413-8804 E-mail: profiraelza@gmail.com

\section{Sacha Maruã Ortiz Siani}

Instituto Nacional de Pesquisas Espaciais Department of Geography, Indiana University E-mail: ssiani@indiana.edu

\section{Patrícia Ortiz Monteiro}

Programa de Educação e Desenvolvimento Humano (UNITAU)

ORCID: https://orcid.org/0000-0002-2944-9050

E-mail: patyortizmonteiro@terra.com.br

Edna Maria Querido de Oliveira Chamon Programa de Educação e Desenvolvimento Humano (UNITAU) ORCID: https://orcid.org/0000-0003-2835-6554 E-mail: edna.chamon@gmail.com

\section{INTRODUÇÃ̃O}

D e acordo com os Parâmetros Curriculares Nacionais, Meio Ambiente PCN/MA ${ }^{1}$ (BRASIL, 1998), a Educação Ambiental (EA) dispõe de ferramentas significativas que podem contribuir para o desenvolvimento da formação identitária do cidadão.

\footnotetext{
1 PCN é a sigla comumente adotada para referência aos Parâmetros Curriculares Nacionais, inclusive pelo próprio Ministério da Educação, que assina o documento.
} 
Essa discussão é retomada com a implantação da Base Nacional Curricular Comum - BNCC (BRASIL, 2017), que aborda a importância da EA no âmbito escolar, por meio de aprendizagem responsável, igualitária individual e coletiva.

Segundo Carvalho (2012), no Brasil a EA desenvolveu-se a partir das preocupações da sociedade com a qualidade de vida, perpassando as esferas de cunho público, ecológico, social e econômico. As primeiras manifestações iniciaram-se na década de 1970, quando, em prol da democracia, surgiram manifestações em toda a América Latina.

Para Sachs (1995), esse período foi um cenário, demarcado por conflitos e práticas punitivas no tocante à liberdade de expressão relacionada aos aspectos políticos, religiosos, étnicos e culturais.

Gradativamente, desponta a necessidade de mudança de paradigma, especialmente por meio de uma educação renovadora e libertadora (DIAS, 2010), cuja propositura são ações concretas que norteiem os envolvidos do âmbito escolar, no comportamento crítico e responsável do homem com o seu MA.

Segundo Bussolotti e Ortiz (2015), a preocupação com os cuidados ao meio ambiente é concomitante ao surgimento da problemática ambiental, mediante ações que impactam o meio ambiente e à medida que ocorre a revolução industrial e a humanidade desenvolve seus conhecimentos.

Considerando a complexidade com que a EA vem se desenvolvendo ao longo da sua história, Monteiro (2017), em sua pesquisa de mestrado em Desenvolvimento Humano, analisa essa temática a partir de um prisma problemático e urgente, apresentando fatos e fatores que impactam a sustentabilidade humana do planeta. Nessa interface, propõe a necessidade de compreender e internalizar os princípios ecológicos e sociais para a prática efetiva da EA contemporânea.

Mediante a relevância dos fatos, neste artigo busca-se relatar pesquisa que analisa as Representações Sociais (RS) de professores atuantes no Ensino Fundamental II de escolas públicas de um município do vale do Paraíba paulista, para compreensão dos significados construídos sobre a EA e sobre o papel destas significações em suas práticas pedagógicas.

A pesquisa envolveu os professores do Ensino Fundamental II e obteve adesão de docentes dos diferentes componentes curriculares da educação formal da Rede Municipal de Ensino. 
O tema motivou outros pesquisadores a estudarem esse objeto, como Ramos (2018), que realizou pesquisas na área da EA para desvendar as RS da EA dos professores atuantes nos anos iniciais do Ensino Fundamental I, em escolas localizadas em um município do sudoeste da Bahia.

Da mesma forma, Araújo (2019) realizou uma pesquisa voltada às RS da EA dos professores de turmas dos anos finais do Ensino Fundamental I, (4o e 5anos) de uma escola pública considerada modelo educacional, em um município da Região Metropolitana do Vale do Paraíba e Litoral Norte (RMVPLN), SP. Explorou o assunto junto aos docentes e 16 pais/responsáveis.

\section{A EA À LUZ DA CARACTERIZAÇÃO DAS CORRENTES E DA TRS}

Os desenhos produzidos nas oficinas foram analisados no contexto das Correntes da Educação Ambiental e à luz da Teoria das Representações Sociais.

De acordo com Suarez e T.B da Silva (2016), delimitar os diferentes campos de atuação da EA não é tarefa simples, pois o surgimento da EA foi em um momento caracterizado como conservacionista, recorrente de problemas ambientais, ainda que resultantes do comportamento social, cultural, político e econômico e que da Corrente de EA Conservacionista surja a proposta de uma EA Crítica.

Para fins deste artigo, optou-se por se concentrar nas correntes Conservacionista e Crítica, devido às diferentes facetas da EA. Segundo Sauvé (2005), por não precisarem ser classificadas de forma rígida, várias correntes se adequam à EA, no entanto sem descaracterizá-la.

Partindo do pressuposto de que a maneira os docentes visualizam a EA pode influenciar as práticas pedagógicas na sala de aula, fez-se necessário investigar suas representações sociais sobre ela, e para isso recorreu-se à Teoria das Representações Sociais - TRS.

Para Moscovici (2011), as RS devem ser observadas sob uma condição peculiar de compreensão, para ser possível decodificar como um grupo representa o que já é sabido por ele, já que as RS emergem da interação entre as pessoas e das informações trocadas, e do modo como o significado ou vários significados concebem às ações.

Com a finalidade de tornar familiar um objeto desconhecido pelo grupo, os indivíduos transformam suas percepções em processos de ancoragem (ação compreendida como um processo que confere ao sujeito vasculhar a sua me- 
mória quando se depara com algo estranho, para torná-lo compreensível) e objetivação (que consiste em conceituar como os sujeitos processam algo subjetivo e o transformam em situação mais apropriada para que a comunicação possa ser entendida pelo grupo) (MOREIRA; CHAMON, 2015).

Nesse sentido, desenvolver a pesquisa no âmbito escolar houve necessidade de esforço para compreender as RS acerca da EA no Ensino Fundamental II, dada a diversidade própria do ambiente onde se encontram os professores, com as suas representações já construídas, oriundas de suas próprias crenças carregadas do conhecimento reificado.

\section{MÉTODO}

Foram utilizados questionários e entrevistas semiestruturadas para caracterizar o perfil sociodemográfico dos sujeitos e, a partir de uma oficina, o grupo realizou desenhos partindo de um roteiro norteador. $\mathrm{O}$ objetivo, neste artigo, é divulgar somente os resultados obtidos a partir dos desenhos utilizados como instrumentos para coleta de dados.

Para preservar a identidade e identificar as escolas foram escolhidos nomes de árvores da flora brasileira: Escola Um - Ipê Amarelo, Escola Dois - Pinheiro do Paraná, Escola Três - Paineira, Escola Quatro - Guapuruvu, e Escola Cinco - Flamboyant.

Os procedimentos de coleta foram desenvolvidos em 3 fases.

A primeira fase da coleta de dados foi realizada a partir da aplicação do questionário semiestruturado. A segunda fase foi a de entrevistas orais, e a terceira e última destinou-se à realização de oficina para a produção dos desenhos.

Segundo Miranda, et al. (2007), os desenhos apresentam caraterísticas mais subjetivas do que respostas escritas ou verbalizadas, configurando um meio legitimo de acessar as informações que acomodam as RS Isso porque possibilitam a apreensão das RS por meio do modo como os sujeitos relacionam significados e imagens.

Recorreu-se ao recurso dos desenhos por considerar que constituem uma maneira lúdica de acessar as RS e a apreensão dos professores sobre a EA. Pressupôs-se que, por se tratar de uma ferramenta que faz parte da rotina do professor, seria adequada para obter os dados objetivados. 


\section{RESULTADOS EDISCUSSÕES}

\section{Análise do perfil sociodemográfico dos professores}

Para obtenção do perfil sociodemográfico dos professores da rede municipal, trabalhou-se com uma amostra de 41 docentes. Os elementos para identificação do perfil sociodemográfico dos sujeitos deste estudo foram: características de sexo, idade, estado civil, renda, turno de trabalho, tempo no exercício da profissão e a disciplina que leciona.

A Tabela 1 apresenta os resultados dos perfis estratificados.

Tabela 1: Distribuição dos professores de acordo com o perfil sociodemográfico

\begin{tabular}{|c|c|c|c|c|c|}
\hline $\begin{array}{l}\text { SEXO } \\
\text { (sujeitos) }\end{array}$ & $\begin{array}{c}\text { MULHERES } \\
n=20\end{array}$ & $\begin{array}{c}\% \\
48,78\end{array}$ & $\begin{array}{c}\text { HOMENS } \\
n=21\end{array}$ & $\begin{array}{c}\% \\
51,22\end{array}$ & $\begin{array}{c}\text { TOTAL (\%) } \\
41=100\end{array}$ \\
\hline \multicolumn{6}{|l|}{ IDADE (anos) } \\
\hline 18 a 25 & 0 & -- & 1 & 2,43 & 2,43 \\
\hline 26 a 35 & 7 & 17,03 & 6 & 14,63 & 31,66 \\
\hline 36 a 45 & 6 & 14,63 & 6 & 14,63 & 29,26 \\
\hline 46 a 55 & 5 & 12,19 & 5 & 12,19 & 24,38 \\
\hline 56 a 65 & 2 & 4,87 & 1 & 2,43 & 7,30 \\
\hline$>65$ & 0 & -- & 2 & 4,87 & 4,87 \\
\hline \multicolumn{6}{|l|}{ Estado civil } \\
\hline Casados & 14 & 34,14 & 13 & 31,70 & 65,84 \\
\hline Solteiros & 3 & 7,31 & 6 & 14,63 & 21,94 \\
\hline Viúvos & 0 & -- & 0 & -- & \\
\hline Separados/Divorciados & 3 & 7,31 & 1 & 2,43 & 9,74 \\
\hline Maritalmente & 0 & & 1 & 2,43 & 2,43 \\
\hline \multicolumn{6}{|l|}{ Renda (s.m)* } \\
\hline 1 a 3 & 2 & 4,87 & 2 & 4,87 & 9,74 \\
\hline 3 a 5 & 9 & 21,95 & 10 & 24,39 & 46,34 \\
\hline 5 a 10 & 8 & 19,51 & 8 & 19,51 & 39,02 \\
\hline 10 a 15 & 1 & 2,43 & 1 & 2,43 & 4,87 \\
\hline$>15$ & 0 & -- & 0 & -- & \\
\hline \multicolumn{6}{|l|}{ *salário mínimo } \\
\hline \multicolumn{6}{|l|}{ Tempo docente } \\
\hline $6 \mathrm{~m}$ a 1 ano & 0 & -- & 2 & 4,87 & 4,87 \\
\hline 1 a 5 anos & 5 & 12,19 & 4 & 9,75 & 21,94 \\
\hline 5 a 10 anos & 5 & 12,19 & 3 & 7,31 & 19,50 \\
\hline 10 a 20 anos & 3 & 7,31 & 10 & 24,39 & 31,70 \\
\hline$>20$ anos & 7 & 17,03 & 2 & 4,87 & 21,90 \\
\hline \multicolumn{6}{|l|}{ Turnos trabalhados } \\
\hline 1 & 2 & 4,87 & 3 & 7,31 & 12,18 \\
\hline 2 & 14 & 34,14 & 14 & 34,14 & 68,28 \\
\hline 3 & 3 & 7,31 & 4 & 9,75 & 17,06 \\
\hline
\end{tabular}

Fonte: Elaborada pelas autoras. 
Os resultados revelam número equilibrado entre professores declarados do sexo feminino e masculino - 51\% homens e $49 \%$ mulheres. Esses dados diferem do perfil informado por Gatti (2010), de que na docência predomina o sexo feminino, $75,4 \%$, em relação ao sexo masculino. Para a autora este não é um elemento novo na educação, tendo em vista o recrutamento de docentes para integrar as primeiras Escolas Normais, desde o final do século XIX, quando as mulheres foram, predominantemente, angariadas para o processo educacional, em relação ao sexo masculino.

O equilíbrio na declaração dos sexos evidenciado neste estudo pode ser decorrente do recorte da pesquisa, que foi direcionada para professores do Ensino Fundamental II com o tema específico da EA.

Na sequência, o Gráfico 1 demonstra os resultados da pesquisa, conforme a distribuição dos professores por componente curricular.

A partir da análise do perfil sociodemográfico, percebeu-se que, de uma amostra de 41 sujeitos, 13 (30\%) são professores de Geografia e Ciências, numa relação de 10 componentes. Os demais estão distribuídos nos diferentes componentes curriculares.

Gráfico 1: Distribuição dos professores por componente curricular

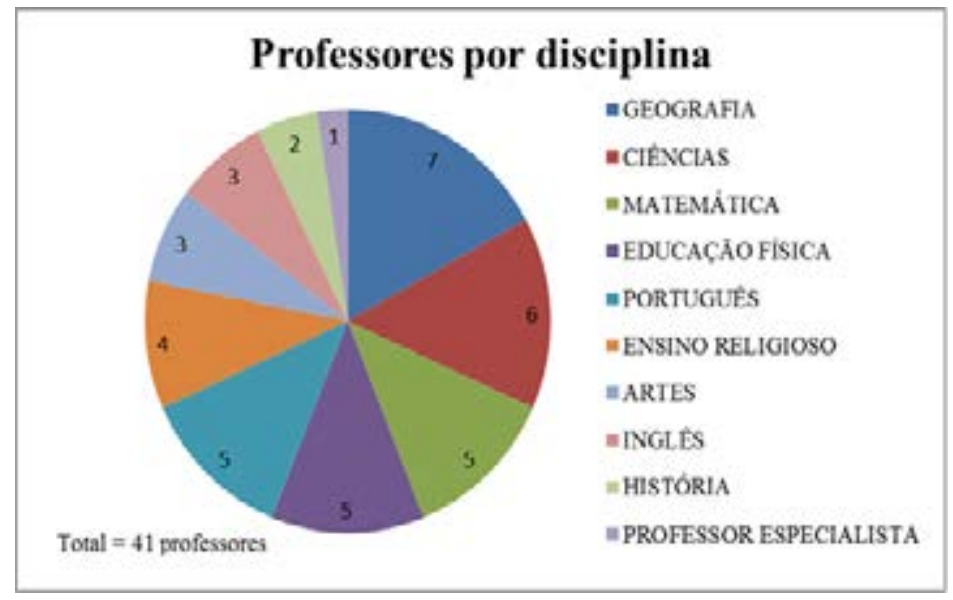

Fonte: MONTEIRO, 2017.

De acordo com Sauvé (2005), a EA pode ser compreendida a partir de elementos voltados à biodiversidade. Nesse contexto, compreende-se por 
que o número de adeptos à pesquisa é referente a docentes de Geografia e Ciências, o que leva a crer que, em função da crença arraigada entre os docentes, a EA ainda é pensada como responsabilidade apenas desses componentes.

Após a conclusão da análise acerca da caracterização do perfil sociodemográfico, passa-se para o estudo dos desenhos.

\section{Análise dos desenhos produzidos pelos professores}

Os resultados dos significados dos desenhos foram analisados à luz da TRS (MOSCOVICl, 2012) e amparada por Moreira e Chamon (2015), quanto ao fato de que as RS dos docentes são guiadas de acordo com os elementos compreendidos por eles no contexto de suas vivências e nas comunicações efetivadas com o meio ambiente.

Segundo Sauvé (2005), a corrente epistemológica da EA tem por premissa apresentar aspectos interpretativos e distintos da EA. São caracterizadas como correntes mais antigas (utilizadas entre as décadas de 1970 e 1980) e entre as mais recentes, mas ambas são tênues e convergem para objetivos comuns.

A análise dos desenhos também se deu mediante a triangulação de dados que, segundo Fígaro (2014), é uma estratégia que atribui fidedignidade aos resultados da pesquisa, sinalizando uma terceira direção quando há diálogo entre dois aspectos em discussão.

\section{Análise da EA nas RS dos docentes em uma abordagem caracterizada como conservacionista}

Os resultados divulgados neste artigo foram analisados de acordo com a compreensão revelada nas RS do grupo docente, considerando a EA voltada às correntes Conservacionista, Crítica e Holística.

De acordo com Araújo, et al. (2019), a Educação Ambiental Conservadora baseia-se na sensibilidade desenvolvida na relação do homem com a natureza, compreendendo uma estreita conexão entre o Meio Ambiente e os 
seus aspectos naturais, desagregados de cunhos políticos, sociais e econômicos. Essa conexão é diferentes nos discursos e nas diversas maneiras de conceber e de praticar a ação educativa, agrupando visões e suposições próprias.

No contexto Conservacionista, a análise de 4 dos desenhos do conjunto das escolas "Ipê Amarelo", "Paineira" e "Flamboyant" evidenciam elementos similares e objetivos comuns, representações que direcionaram o entendimento dos resultados para ações concretas da EA.

Os 2 desenhos da escola "Ipê Amarelo" demonstram que as representações revelam necessidades práticas da EA para a escola e o seu entorno.

Figura 1 - Escola Ipê Amarelo: fossa séptica e orgânicos

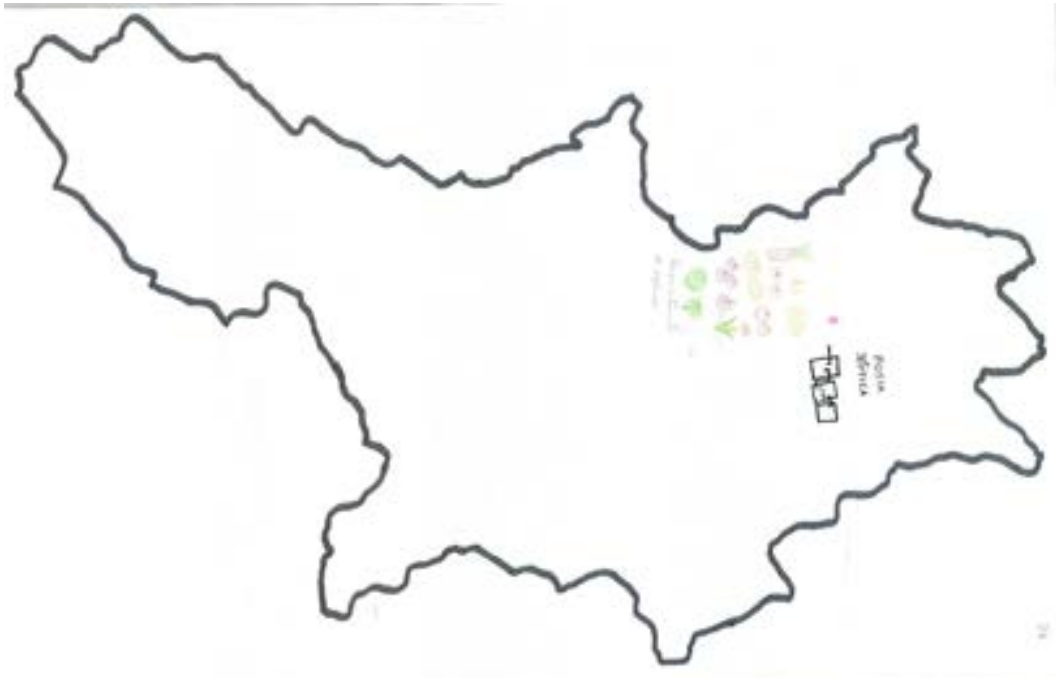

\section{Escola Ipê Amarelo}

LEGENDA: Fossa séptica e Reaproveitamento de orgânicos.

De acordo com as urgências visualizadas pelos docentes, há necessidade urgente de construção de fossas sépticas . Como está inserida na zona rural, a comunidade conta apenas com uma pequena fossa, sem esgoto encanado. Bucam uma resolução rápida dos problemas ambientais locais, convergindo para uma EA Conservacionista, sem, no entanto, perceberem a escola inserida no contexto. 
Figura 2 - Escola Ipê Amarelo: Reciclagem

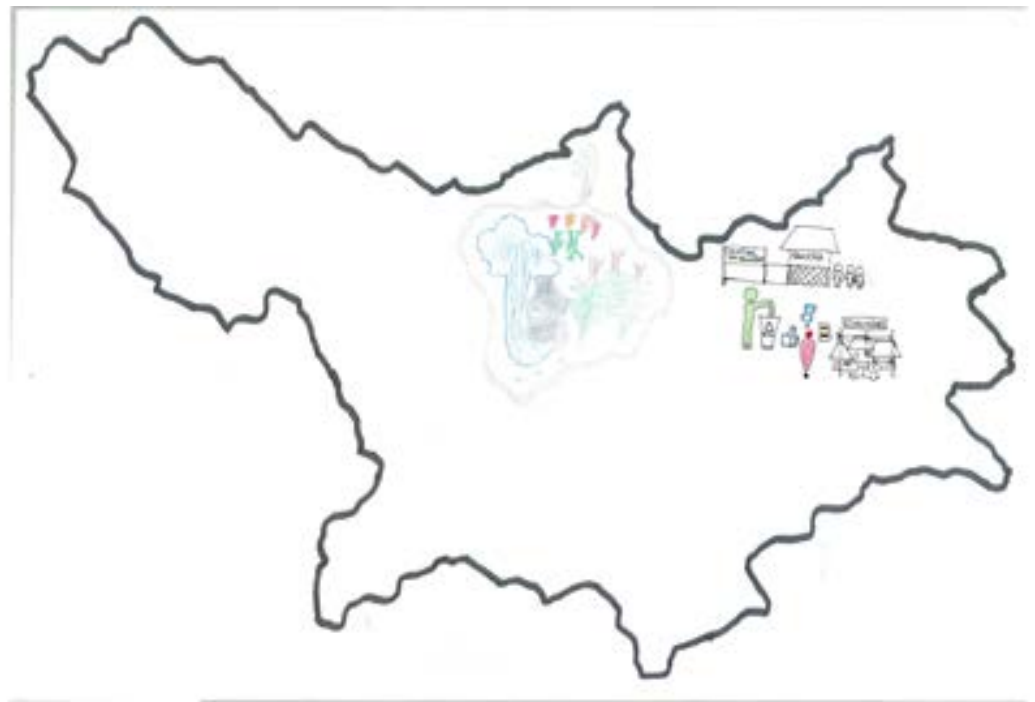

Escola Ipê Amarelo

LEGENDA: Escola; Central de Reciclagem

NARRATIVA SOBRE O DESENHO: Então, a gente teve ideias de fazer o seguinte, as mídias sociais, colocando a comunidade e escola no espaço geográfico né? [...] falando sobre o meio ambiente, sobre a poluição, a preservação do ambiente, da biosfera, da ecosfera. É, acho que é isso.

A narrativa relacionada ao desenho evidencia que as RS dos docentes são construídas a partir de questões mais "urgentes", o que permite compreender que os seus significados estão relacionados a ideia de bem-estar, o que não é uma preocupação recente. Segundo Loureiro et al. ( 2012), as preocupações com saneamento básico retomam a Idade Média. Essa abordagem conduz ao olhar Conservacionista do grupo, e observou-se que as suas RS sobre EA se constroem a partir da inquietude acerca dos problemas reais, vivenciados por eles e pela comunidade local.

Na sequência, os desenhos analisados são das escolas identificadas como "Paineira" e "Flamboyant". A do contexto urbano, conduzem para uma compreensão próxima à corrente Conservacionista, ao fazer referências às necessidades de conservação dos recursos naturais no contexto vale paraibano. 
Figura 3 - Escola Paineira: as cinco ações

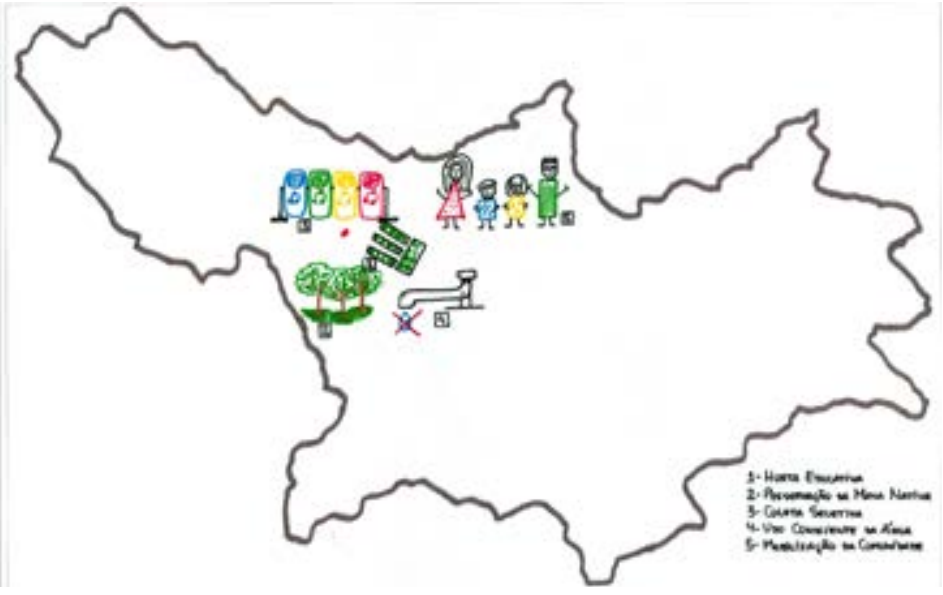

\section{Escola Paineira}

LEGENDA: Horta educativa; Preservação da mata nativa; Coleta seletiva; Uso consciente da água; Mobilização da comunidade.

NARRATIVA SOBRE O DESENHO: Nosso desenho foi representado por cinco ações, cinco atividades que nós poderíamos fazer: [...] tem que ser algo em conjunto, partindo dos alunos, das necessidades, do conhecimento que eles têm e também das matérias que nós desenvolvemos na escola.

Figura 4 - Escola Flamboyant: plantio de árvores

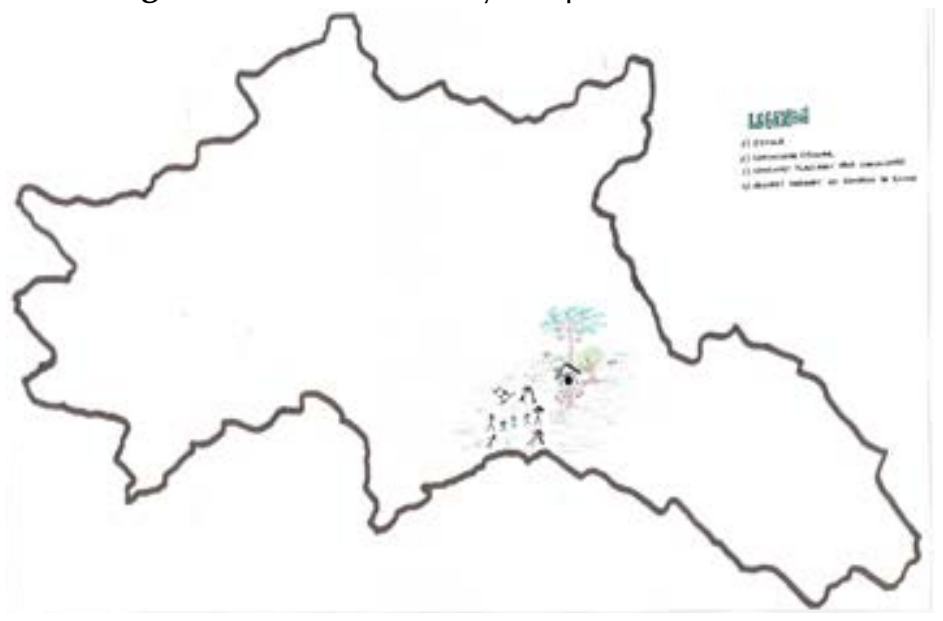

\section{Escola Flamboyant}

LEGENDA: Escola; Comunidade escolar; Sementes plantadas pela comunidade; Árvores variadas no entorno da escola. 
NARRATIVA SOBRE O DESENHO: Compartilhar as ideias. Bom, a gente pensou o entorno escolar com as árvores e a preservação que já tem [...] para refletir um pouco sobre a necessidade do verde que existe hoje em dia, da preservação.

As narrativas reforçam as representações evidenciadas nos desenhos, de que o grupo de professores expressa necessidades básicas do cotidiano escolar, como as coletas seletivas, hortas educativas, economia no consumo hidráulico, porém enfatizando a importância de reflexões para mudanças comportamentais de atitudes e valores que envolvem a escola e a comunidade escolar.

Compreende-se que o repertório de significados da RS dos professores acerca da EA e os desafios encontrados estão em consonância com os desenhos. Essas revelações devem consideradas, pois a EA é apontada como principal fonte de responsabilidades para mudanças de postura.

Se a linha das Correntes de EA são tênues (Sauvé, 2005), há de se concordar com Reigota (2011): mesmo que os docentes representem uma intenção conservacionista, é importante compreender que estão buscando exercitar o pensamento crítico, que está mais válido que nunca.

O conjunto dos desenhos analisados demonstra uma disposição conservacionista dos docentes, relativa às ações da EA no contexto escolar (MONTEIRO, 2017), mas em suas tentativas estão buscando meios para desenvolver ações da maneira que lhes é possível.

\section{Análise da EA nas RS dos docentes em uma abordagem mais Crítica}

Carvalho (2012) defende que a EA pertence à corrente Crítica, ao se manifestar sobre o campo que conduz às reflexões combinada com as ações, cujas ferramentas podem contribuir e garantir melhorias na aprendizagem formal e informal.

Desse modo, a análise realizada nos desenhos das escolas identificadas como Flamboyant, Ipê Amarelo e Paineira demonstra que as linguagens caminham para uma discussão voltada à EA Crítica, permeando mudanças de hábito e responsabilidade socioambiental vivenciadas e necessárias no cotidiano. 
Figura 5 - Escola Flamboyant: Projeto Escola Consciente

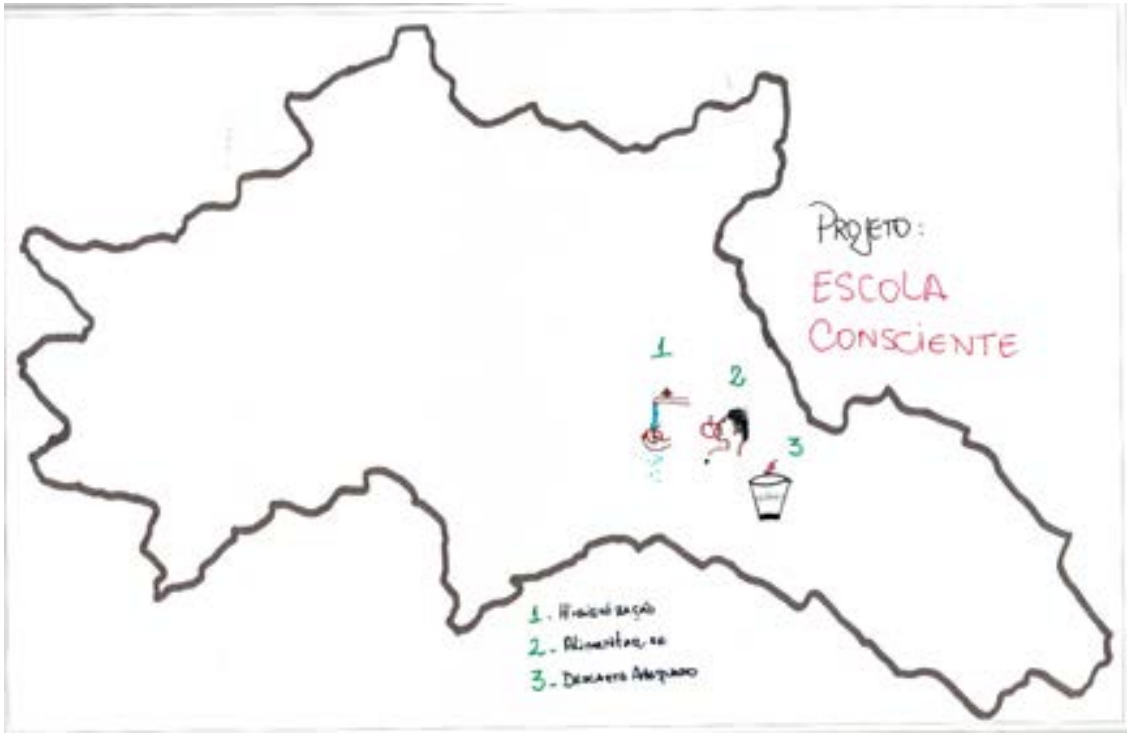

Escola Flamboyant

LEGENDA: Projeto ESCOLA CONSCIENTE; 1-Higienização; 2-Alimentar-se; 3-Descarte adequado.

As RS da EA para os docentes são manifestadas de formas simples, como a organização nas próprias salas de aula, respeito ao patrimônio público, respeito junto aos colegas. São transformações que servirão de base suficiente para conduzir os alunos a dar continuidade a esse hábito, tanto no contexto escolar quanto no seio familiar. Essas transformações estão voltadas à ressignificação da relação entre o homem e o meio ambiente.

Os resultados analisados revelam uma corrente voltada à corrente Crítica da EA, referenciando a escola como "escola consciente" no que concerne, entre outros aspectos, a higienização, alimentação, descartes corretos do lixo.

De acordo com Chamon e Chamon (2007), observou-se que as RS dos professores se destacam em relação à temática da EA voltada à ressignificação da relação social entre o homem ativo e sua capacidade de reconstruir-se com base na aprendizagem que já possui.

Sendo assim, o desenho apresenta a escola como núcleo e eixo central para o desenvolvimento da EA, evidenciando que o conhecimento e com- 
preensão dos alunos referentes ao contexto escolar podem ser levados para outras instâncias.

Figura 6 - Escola Paineira: a escola e a comunidade

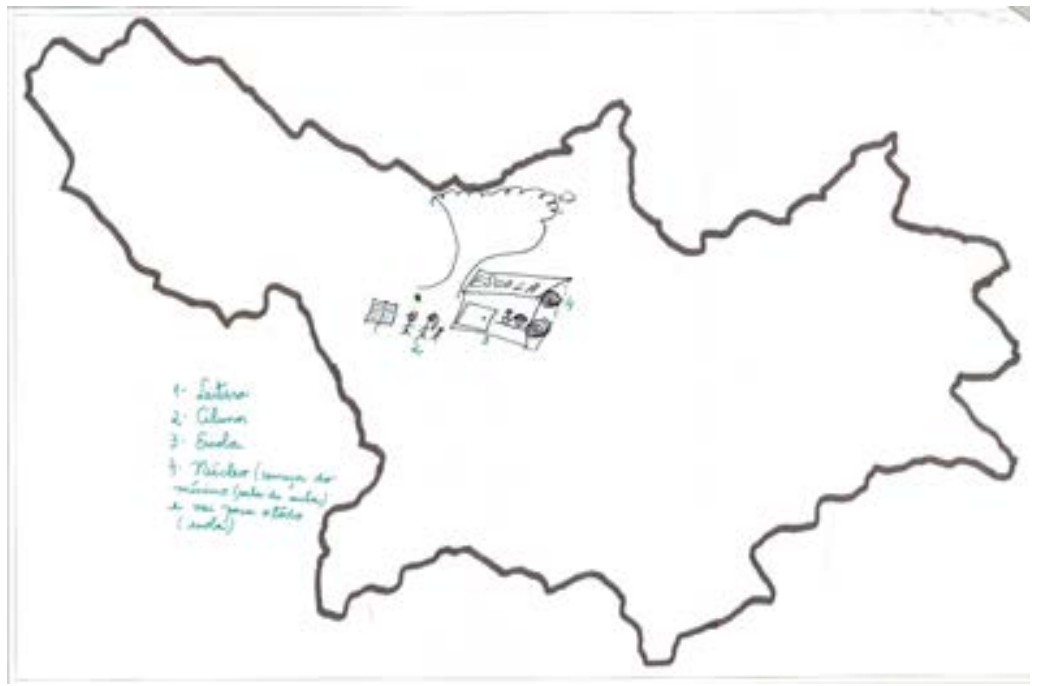

\section{Escola Paineira}

LEGENDA: Leitura; Alunos; Escola; Núcleo (começa do mínimo [sala de aula] vai para o todo [escola]).

NARRATIVA SOBRE O DESENHO: O desenho dentro do contexto de Educação Ambiental. Bom, imaginamos uma Educação Ambiental, não restritamente à escola, mas inserida dentro de uma comunidade. [...] Acho que a nossa ideia é mais abrangente, daí envolve uma política pública relacionada ao meio ambiente.

Na visão dos professores, a EA deve ser implementada pelas Secretarias de Educação e de Meio Ambiente, e o apoio pedagógico, sobretudo, deve ser sistemático e coletivo, como revelam seus desenhos.

Na próxima imagem analisada, o grupo assume a representação de que as questões ambientais são imprescindíveis na formação de caráter do cidadão, ao mesmo tempo em que dá uma conotação de pertencimento entre aluno, escola, professor e comunidade.

As RS trazem preocupações voltadas à escola inserida no espaço, considerando as dimensões geográfica, temporal e social, imprescindíveis na manutenção efetiva das ações.

Segundo Siani (2017, página 45): 
As APAs são Unidades de Conservação (UCs) de uso sustentável, destinadas a proteger e conservar a qualidade ambiental e os sistemas naturais existentes, visando melhorar a qualidade de vida da população local e a proteção dos ecossistemas.

Figura 7 - Escola Paineira: espaço escolar

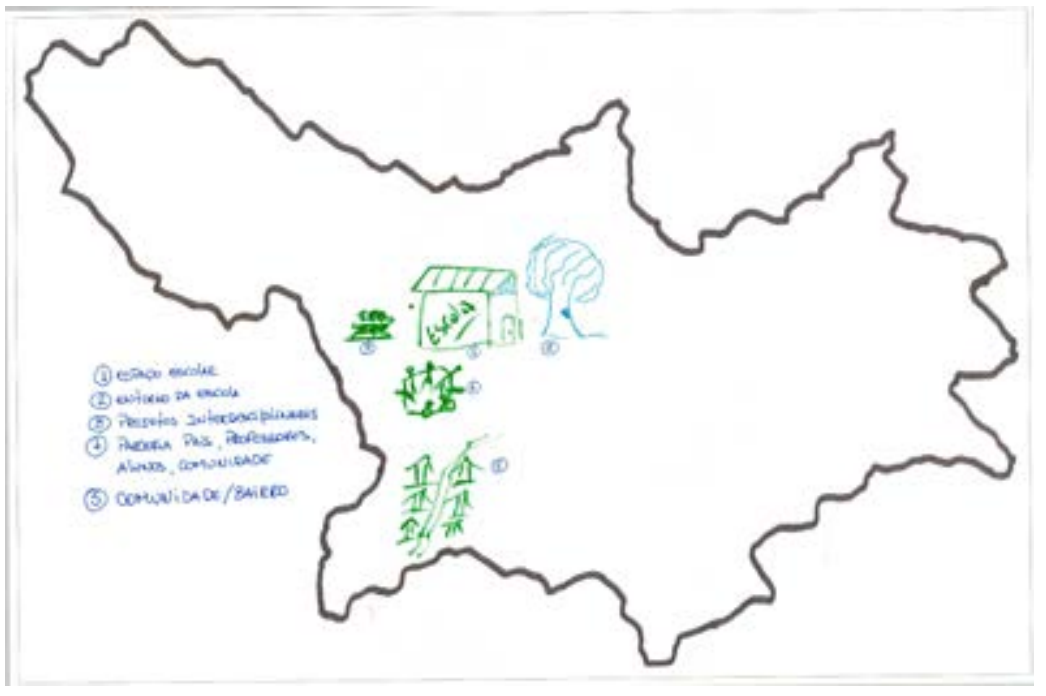

\section{Escola Paineira}

LEGENDA: Espaço escolar; entorno da escola; projetos interdisciplinares; parceria pais, professores, alunos, comunidade; comunidade/bairro.

Com vistas ao entendimento de Siani (2017), incentivar a criação de unidades de conservação ambiental nos municípios, principalmente próximas às escolas limítrofes a essas áreas, é uma saída importante e necessária para motivar os atores escolares à exploração do conhecimento acerca do uso sustentável dos recursos ambientais, objetivando atender ao apelo da EA.

Para completar a análise dos desenhos considerados como contexto da EA Crítica, destaca-se a próxima produção, cujas manifestações pertencem ao grupo de professores da escola Ipê Amarelo, localizada na zona rural do município.

$\mathrm{Na}$ produção foram encontradas evidências de que as RS da EA extrapolam o cenário escolar e o da comunidade do entorno. Os elementos encontram-se contextualizados em uma região afastada do centro urbano, 
mas não deixam de ressaltar a importância de envolver todo o município nas responsabilidades relativas à EA.

Na linguagem do grupo - Somos nós, por isso as digitais no desenho, então depende de nós fazer a mudança -, as mudanças devem começar pelos envolvidos no processo de ensino e aprendizagem. Por meio da arte abstrata o grupo expressou que as digitais registradas são dos professores, que precisam demarcar um significado relacionado à própria identidade.

Figura 8 - Escola Ipê Amarelo: nós fazemos a mudança

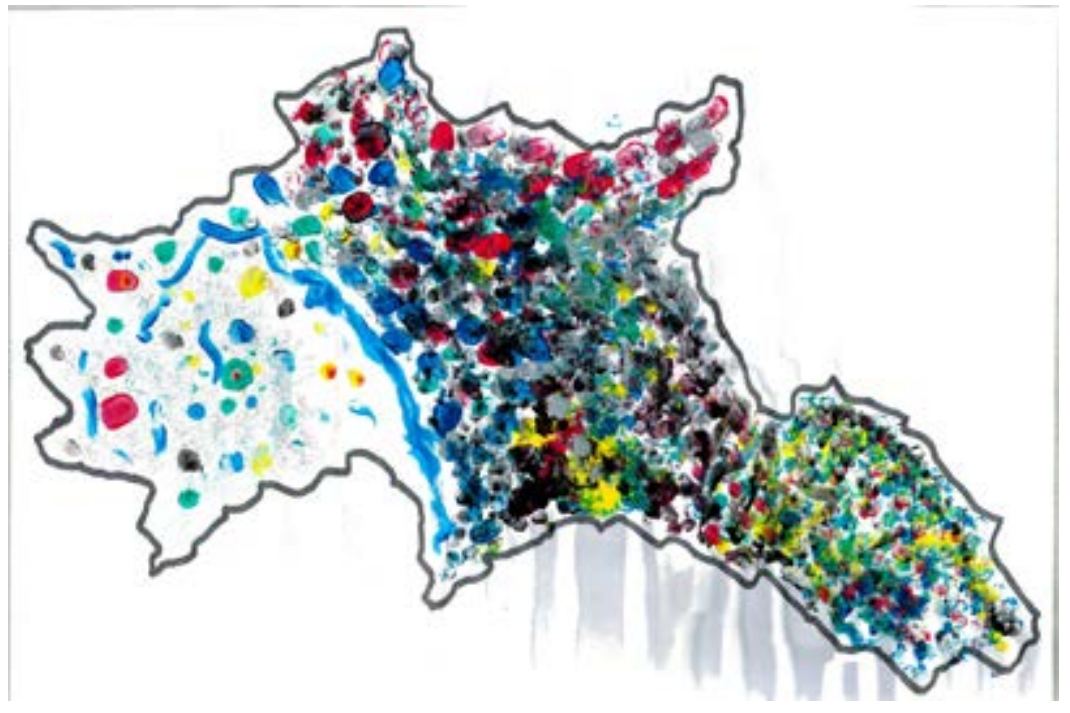

Escola Ipê Amarelo

LEGENDA: Não apresenta.

NARRATIVA SOBRE O DESENHO: A ideia do desenho aqui é mostrar [...]. Somos nós, por isso as digitais no desenho, então depende de nós fazer a mudança.

Para Moscovici (2012), essas RS são reflexos das emoções e dilemas cognitivos, que, ao serem expressos em signos, auxiliam o diálogo entre as representações internas e externas.

Conforme define Loureiro (2012), as relações são construídas a partir das interações sociais estabelecidas entre os indivíduos com a natureza. Assim, acredita-se que os docentes se dispõem a enveredar por caminhos que conduzam às reconstruções nas formas de aprender e de ensinar, com as 
quais possam adquirir segurança e autonomia para interferir nas decisões e na elaboração de políticas públicas.

O próximo e último desenho pertence ao conjunto de professores da escola identificada como "Flamboyant". Observa-se que as RS dos docentes se organizam entre noção de responsabilidade e harmonia do homem com o meio ambiente. De acordo com a análise, esses encaminhamentos levam a entender que as interpretações percorrem as correntes EA Holística e EA Crítica.

Para Sauvé, (2005), a Corrente Holística explora as múltiplas dimensões do conhecimento total do ser orgânico na interação com o meio ambiente, com estratégias criativas além dos muros da escola, em operações reais. Segundo Araújo et al. (2019), são complexidades apresentadas pela EA Crítica, por meio da qual os indivíduos compartilham preocupações com a realidade socioambiental.

Figura 9 - Escola Flamboyant: a árvore Guapuruvu

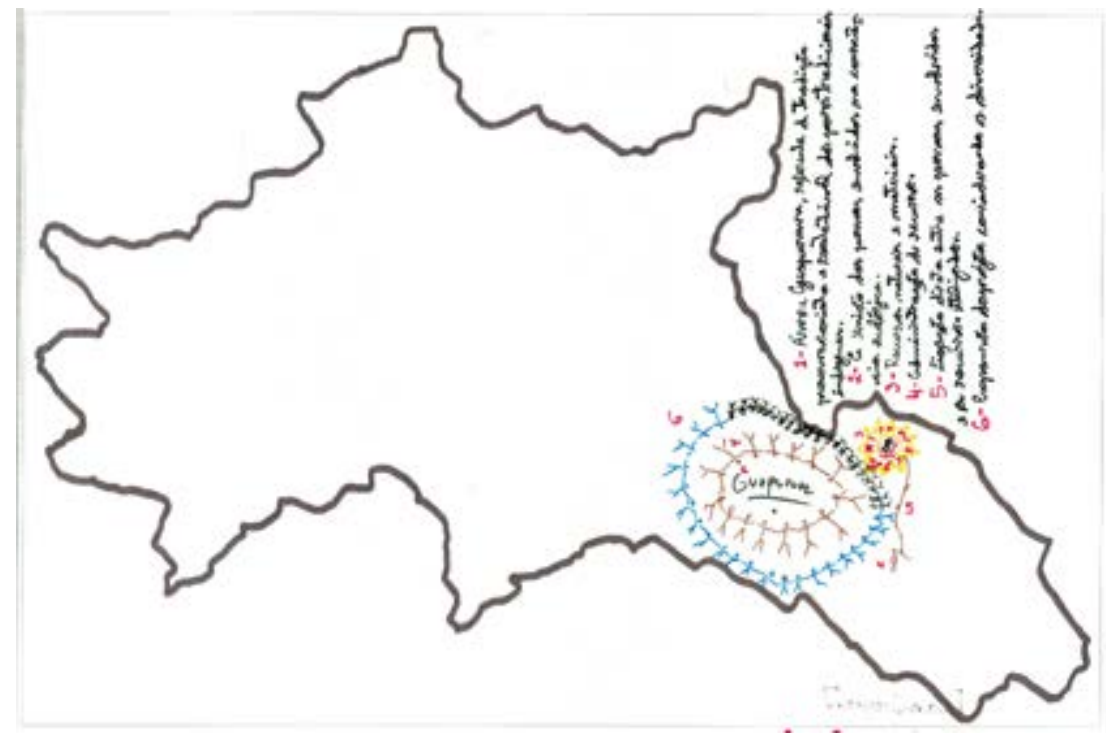

\section{Escola Flamboyant}

LEGENDA: 1-Árvore Guapuruvu, referente à tradição preservacionista e sustentável dos povos tradicionais indígenas; 2-A união das pessoas envolvidas na consciência ecológica; 3-Recursos naturais e materiais; 4-Administração de recursos; 5-Ligação direta entre as pessoas envolvidas e os recursos utilizados; 6-Expansão do projeto considerando a diversidade. 
As figuras humanas representadas no desenho estão de mãos dadas. Organizam-se em círculo e circundam a árvore denominada Guapuruvu, que, segundo o grupo, é símbolo das tradições dos indígenas, que lutam pela preservação da cultura ambiental.

Partindo desse imaginário, o grupo traduziu a necessidade da união das pessoas em prol da consciência ecológica. Os registros evidenciam o respeito à tradição preservacionista e sustentável dos povos indígenas. Reigota (2011) explica que a noção de ecologia está atrelada à natureza, e que ecologismo significa buscar preservá-la. Nesse sentido, ambas as definições estão presentes na mensagem do grupo. Monteiro (2019) define que as RS analisadas levam a crer que a escola é pensada como um espaço socioambiental privilegiado para o diálogo interdisciplinar, harmônico, entre a prática e disseminação dos saberes, favorecendo a criação de uma identidade de valores e ações solidárias, aliada a uma perspectiva ecológica romantizada das tradições.

Diante do exposto, compreende-se que as reflexões, segundo as RS dos professores, perpassam a relação homem e meio ambiente e fazem frente a uma discussão pertinente à contemporaneidade social (MONTEIRO; ORTIZ MONTEIRO, 2017), a de que a escola, apesar da sua complexidade, ainda é o cenário mais indicado para propiciar condições de aprendizagem.

\section{CONSIDERAÇÕES FINAIS}

Considerando a subjetividade de análise dos desenhos, foi possível identificar as RS da EA para os professores e como orientam as práticas cotidianas nas escolas de Ensino Fundamental II.

A partir da reflexão sobre os desenhos, as legendas e as narrativas, perceberam-se semelhanças significativas entre as escolas do município, na prática da EA.

Verificou-se que as RS dos docentes a respeito da EA nas escolas de Ensino Fundamental II são construídas a partir de discussões que despertam o interesse para o desenvolvimento da consciência tradicional e crítica, e ao mesmo tempo romantizada, diante das dificuldades apontadas no contexto da escola pública, sem ênfase nas práticas. 
Nas discussões acerca da efetividade da EA nas escolas, há indícios de que os sujeitos pesquisados creem que estão sendo desenvolvidas ações significativas próprias da EA, mas ao mesmo tempo destacam os desafios enfrentados pela falta de conhecimento especifico da temática. Esse foi o maior problema apontado para o não desenvolvimento de ações concretas.

Os docentes pesquisados almejam mudanças, todavia evidenciam a falta de iniciativas para começar ou efetivar as ações. A discussão sobre a EA nas escolas aparece de forma fragmentada, em abordagens pontuais, como saneamento básico, plantio de árvores, resíduos sólidos, entre outros, o que reduz o potencial que a EA, se desenvolvida no contexto efetivo do termo, pode proporcionar.

Os desenhos alusivos à EA representam, neste estudo, o entendimento dos professores de como deveria ocorrer a EA no cotidiano escolar; contudo, não há demonstração evidente de que todos os professores a concretizem na escola, mesmo que sinalizem a necessidade de formação continuada para trabalhar a EA. Ao evidenciarem as responsabilidades da formação para os órgãos públicos, os professores reconhecem que é na escola que as coisas acontecem.

Os resultados demonstram que as RS da EA no trabalho docente nas escolas depende de uma diretriz que possibilite a sistematização de práticas pedagógicas. Para o desenvolvimento de ações no eixo temático relativo à EA, aponta-se a necessidade de programas de formação continuada.

O modo como os professores apreendem a EA pode refletir nas práticas e na maneira como vêm sendo representados as metodologias e os conceitos da EA na educação formal. Assim, os resultados não devem produzir efeitos significativos. Acredita-se que uma real implantação da EA nos currículos escolares conduza a questões ambientais prósperas, bem como venha a despertar o protagonismo de professores e alunos, e o envolvimento da comunidade.

Resumo: No presente artigo são analisados e reportados os resultados de uma pesquisa sobre as Representações Sociais (RS) relativas à Educação Ambiental (EA). A pesquisa foi realizada com um grupo de professores de Ensino Fundamental II do sistema público no Vale do Paraíba paulista. A abordagem baseia-se em análise descritiva de dados qualitativos. A coleta de dados foi realizada em três etapas: primeiro, foram aplicadas entrevistas semiestruturadas sobre educação ambiental à uma amostra de 41 professores. Segundo, 25 docentes dessa amostra participaram de uma oficina de desenhos. Finalmente, na terceira etapa, utilizou-se um questionário para coletar informações sociodemográficas dos professores. Os dados qualitativos foram sistematizados no 
programa Alceste e classificados em agrupamentos de discurso. Nesta pesquisa, foram analisados os perfis sociodemográficos e 9 desenhos que sintetizam as representações dos professores a partir de suas compreensões sobre Educação Ambiental. A análise dos desenhos foi amparada no aporte teórico referente à Teoria das RS, e para o tratamento dos dados utilizou-se a estratégia da triangulação, que conferiu fidedignidade aos discursos dos professores. Os resultados dessa pesquisa revelaram que as RS dos professores acerca da EA no Ensino Fundamental II manifestam reflexões coligadas à teoria, à prática escolar e às necessidades do cotidiano escolar, em relação às responsabilidades vinculadas entre escola e família, sociedade e meio ambiente e com vistas ao desenvolvimento humano entre as correntes Conservadora e Crítica. Além disso, os dados evidenciam a prática de sala de aula como um dos elementos estruturantes das RS dos professores que ainda é frágil. Isso sugere que a relação de pertencimento às questões ambientais e a problemática socioambiental ainda dependem de criação de políticas públicas, capacitação de professores e coparticipação da comunidade escolar e da sociedade.

Palavras-chave: Desenvolvimento Humano; Educação Ambiental; Representações Sociais; Ensino Fundamental.

\begin{abstract}
Here, we analyze and report the results of a survey on Social Representations related to Environmental Education. The survey was carried out with a group of Middle School teachers from the public system in the São Paulo Valley. Our research uses a qualitative, descriptive, applied and exploratory approach. Our research uses a qualitative, descriptive, applied, and exploratory approach. Data collection was carried out in three stages: first, semi-structured interviews on environmental education were applied to a sample of 41 teachers. Second, 25 teachers from this sample participated in a drawing workshop. Finally, we used a questionnaire to collect sociodemographic information from teachers. Qualitative data were systematized in the Software Alceste and classified into groups of discourse. In this article, we analyzed the sociodemographic profiles and nine drawings that synthesize the representations of teachers from their understanding of Environmental Education. The analysis of the drawings was supported by the theoretical contribution referring to the Theory of Social Representations, and for the treatment of the data, the triangulation strategy was used, which gave reliability to the teachers' speeches. The results of this research revealed that the teachers' Social Representations about environmental education in the middle school manifest reflections related to the theory, the school practice, and the needs of the school day-to-day, concerning the responsibilities linked between school and family, society, and the environment and with a view to human development between the Conservative and Critical currents. In addition, the data show the classroom practice as one of the structuring elements of the teachers' Social Representations, which is still fragile. This suggests that the relationship of belonging to environmental issues and socio-environmental problems still depends on the creation of public policies, teacher training, and co-participation by the school community and society.
\end{abstract}

Keywords: Human development; Environmental Education; Social Representations; Middle school.

\title{
REFERÊNCIAS
}

ARAÚJO, R G. D. S.; ORTIZ MONTEIRO, P. D. E. B. de S. C. et al. Educação Ambiental no Ensino Formal: um projeto desenvolvido em uma escola pública modelo. Educação Ambiental e Desenvolvimento Humano [recurso eletrônico]: pesquisas e práticas/ Patricia Ortiz Monteiro, Juliana Marcondes Bussolotti (Orgs). - Dados eletrônicos Taubaté: EdUnitau, 2019. Acesso em: 24 jun. 2019.

BRASIL. Ministério da Educação. Parâmetros Curriculares Nacionais: Meio Ambiente. Brasília: 1998. Disponível em:<portal.mec.gov.br/seb/arquivos/pdf/meioambiente.pdf > . Acesso em 17/05/2015.

BRASIL. Ministério da Educação. Base Nacional Comum Curricular. Educação é a base. Brasília, 2017.

BUSSOLOTTI, J.; ORTIZ. P. Educação Ambiental para Sustentabilidade. Livro texto para Programa de Educação a distância da Universidade de Taubaté, Taubaté: UNITAU, 2015. 
CARVALHO, Isabel Cristina de Moura. Educação Ambiental: a formação do sujeito ecológico. 6. ed. São Paulo: Cortez, 2012.

CHAMON, E. M. Q. O.; CHAMON, M. A. Representação Social e Risco: Uma abordagem Psicossocial. In: CHAMON, E. M. Q. O. (org). Gestão de organizações públicas e privadas: Uma abordagem interdisciplinar. Rio de Janeiro: Brasport, 2007. p. 79-102.

DIAS, Genebaldo Freire. Educação Ambiental: princípios e práticas. 9. ed. São Paulo: Gaia Global, 2010.

FÍGARO, R. A Triangulação Metodológica em Pesquisas sobre a Comunicação no Mundo do Trabalho. Revista Fronteira - estudos midiáticos, v. 16, n. 2, p. 124-131, maio/ago. 2014. Disponível em: http://revistas.unisinos.br/index.php/fronteiras/article/viewFile/fem.2014.162.06/4196. Acesso em: 18 nov. 2016.

GATTI, B. A. Formação de Professores no Brasil: Características e Problemas. Educ. Soc. Campinas, v. 31, n. 113, p. 1355-1379, out.-dez. 2010. Disponível em: https://www.scielo.br/pdf/es/ v31n113/16.pdf. Acesso em: 18 jun. 2020.

GUARESCHI, P., ROSO, A. Teoria das Representações Sociais - sua história e seu potencial crítico. In: CHAMON, E. M. Q. O; GUARESCHI, Pedrinho Arcildes; CAMPOS, Pedro Humberto Faria (orgs). Textos e debates em representação social. Porto Alegre: ABRAPSO, 2014.

LOUREIRO,C. F. B. et al. Sociedade e meio ambiente: a educação ambiental em debate. 7. ed. São Paulo: Cortez, 2012.

MIRANDA, Fan et al. Figuras e significados: recursos gráficos na pesquisa de representações sociais. Rev. Eletr. Enf. 2007; 9 (2):526-36. Disponível em: <http://www.fen.ufg.br/revista/v9/n2/ v9n2a19.htm> Acesso em: 14 fev. 2016.

MONTEIRO, I. F. C. Representações Sociais na Educação Ambiental para professores do Ensino Fundamental II. 2017. Dissertação (Mestrado em Desenvolvimento Humano) - Universidade de Taubaté, Taubaté, 2017. Banco de dados UNITAU.

MONTEIRO, I. F. C.; ORTIZ MONTEIRO, P. D. E. B. de S. C. A Educação Ambiental e as representações sociais dos professores da rede pública no ensino fundamental. Revista Brasileira de Educação Ambiental, v. 12, n. 1, p. 165-176, 2017. https://doi.org/10.34024/revbea.2017.v12.2391.

MONTEIRO, I. F. C. Representações sociais da educação ambiental, uma análise com professores do Ensino Fundamental II de uma Rede Pública. In: ABDALA, R. D.; Almeida, R. de S. (Orgs.) Formação, Desenvolvimento Humano e Interdisciplinaridade. Taubaté-SP: EdUnitau, 2018.

MONTEIRO, I. F. C.; ORTIZ MONTEIRO, P. D. E. B. de S. C. A Educação Ambiental nas Representações Sociais de professores e a importância da Sala Verde. EccoS - Rev. Cient., São Paulo, n. 48, p. 201-218, jan./mar. 2019. Disponível em: https://periodicos.uninove.br/eccos/article/ view/7285/6621. Acesso em: 07 jul. 2020.

MOREIRA, A. M.; CHAMON, Edna Maria Querido de Oliveira. Ser professor: representação social e construção identitária. - 1. ed. Curitiba: Appris, 2015.

MOSCOVICl, S. Investigações em psicologia social. Tradução: Pedrinho Arcides Guarechi. 9. ed. Petrópolis: Vozes, 2012.

MOSCOVICl, S. Representações sociais: investigações em psicologia social. 8. ed.-Petrópolis, RJ: Vozes, 2011.

RAMOS, M. T.; ORTIZ MONTEIRO, P. D. E. B. de S. C. Representações Sociais de professores em Educação Ambiental de escolas públicas municipais. Revista Brasileira de Educação Ambiental, 
v. 13, n. 4, p. 281-297, 2018. https://doi.org/10.34024/revbea.2018.v13.2648 Disponível em: https://periodicos.unifesp.br/index.php/revbea/article/view/2648 Acesso em: 19 jun. 2020.

REIGOTA, M. A floresta e a escola: por uma educação ambiental pós-moderna. 4. ed. São Paulo: Cortez, 2011.

SACHS, Ignacy: Em busca de novas estratégias de desenvolvimento. Estudos avançados 9 (25), 1995. Disponível em: http://www.scielo.br/pdf/ea/v9n25/v9n25a04.pdf. Acesso em: 14 abr. 2017.

SAUVÉ, L. Uma cartografia das correntes em Educação Ambiental. SATO, M.; CARVALHO, I. C. M. (Orgs.). Educação Ambiental - pesquisas e desafios. Porto Alegre: Artmed,2005. Disponível em: web.unifoa.edu.br/portal_ensino/mestrado/mecsma/arquivos/sauve-I.pdf. Acesso em 18 jun. 2017.

SIANI, S. M. O. iSAM - Um sistema de indicadores para o monitoramento da Área de Proteção Ambiental Mananciais do Rio Paraíba do Sul. Instituto Nacional de Pesquisas Espaciais. Revista do Departamento de Geografia, São Paulo, v. 33, p. 63-73, 2017. Disponível em: http://www. revistas.usp.br/rdg/article/view/119663/132867. Acesso em: 18 jun. 2020.

SUAREZ, Ana Paula; T. B da SILVA, A. M. De qual Educação Ambiental estamos falando? Uma Análise dos mestrados profissionais do Rio de Janeiro. Ebook: Novas Edições Acadêmicas, 2016.

Recebido em Dezembro de 2020 Aprovado em Março de 2021 